\title{
Assessing the Impact of NAADS Programme on Agricultural Economic Performance in Mbarara District
}

\author{
Tamson Nuwagaba $\mathbf{K}^{*}$, Firimooni Banugire $\mathbf{R}$ and Nuwabiimpa Milton $\mathbf{R}$ \\ Department of Business and Development Studies, Bishop Stuart University, Uganda
}

\begin{abstract}
This study was conducted on assessing the impact of NAADS programme on agricultural economic performance in Mbarara district. Agricultural Economic performance was assessed in terms of household income and commercialization. The study was done in two Sub-Counties i.e., Nyamitanga and Mwiizi S/County to represent Mbarara district. A sample of 132 respondents was used of both NAADS and Non-NAADS farmers in both Goat rearing and Piggery and NAADS Coordinators who were involved in the programme from the district to Parish level in Mbarara district. Both stratified and purposive sampling were used to select the sample in both Mwiizi sub-county and Nyamitanga division as, 63 NAADS farmers of both enterprises (goat and pig rearing) and 6 NAADS Coordinators from two S/Counties as well as 63 Non-NAADS farmers from the same enterprises in both sub-counties. The study used both questionnaire survey and interview methods in collecting data from the field.

The study adopted a Quasi-experimental research design where difference in difference model was used. The Difference between means was used to determine if there is a significant difference between NAADS and NonNAADS on economic outcomes of commercialization and household income in Mbarara district. The primary data was collected using questionnaire survey and interview methods and analyzed using SPSS.

The findings show that there was no significant difference on level of commercialization in terms of technology adoption; household income in both NAADS and Non-NAADS farmers involved in goat rearing and piggery in Mbarara district.

Basing on the findings, the level of monitoring and supervision, distribution of farm inputs and service delivery, fund flows to facilitate the coordinators and service providers, and purchase inputs, farm inputs to distribute to farmers, attitude of farmers towards government programmes and corruption and embezzlement of funds were the most important factors that greatly affected the economic performance of NAADS programme in Mbarara district.

In recommendation, the government should increase the level of monitoring and supervision at different levels, increasing in the accessibility of inputs and service delivery, anti-corruption and embezzlement laws, allocation of enough funds, empowerment of the institutions like the local government, farmer groups and other civil society organisations (CSOs), increase on the level of accessibility through fair distribution of farm inputs and encourage pilot studies in area where the programme is to be implemented.
\end{abstract}

Keywords: Economic; Farmer; Agro-industrial; Uganda

\section{Background}

Around the world, countries have tried so much to put up some programmes to increase on the level of agricultural production. In countries like china, California etc. have programme to improve on agricultural productivity and food security.

In Africa, different countries like Mali, Nigeria, Botswana, etc. have introduced and implemented agricultural reforms/ programmes/ policies to increase on agricultural production (in both livestock and crop production) through increase productivity, and market-oriented farming to promote food security, agricultural exports and poverty reduction in the economy.

For instance, in West Africa (Mali) New varieties of tomatoes were introduced by the West African Agricultural Productivity Program (WAAPP) and allowing Malian farmers to continue producing crops during the rainy season (Moussa Diarra/World Bank 2014). The program also encouraged research and development especially in higher yielding rice varieties (Moussa Diarra/World Bank 2014).

The West Africa Agricultural Productivity Program (WAAPP) also worked hard to bolster research and extension of agricultural technologies in Ghana, Mali, and Senegal, focusing on the top agricultural priorities of each country. As of September 2012, 253,881 individuals had benefited directly from the project, and 37 new technologies were released, improving 166,938 hectares of land (Moussa Diarra/World Bank 2014).

In Uganda, agriculture is the most important sector in the economy but the performance has not been impressive. Therefore, it has been undergoing different reforms to increase agricultural production and productivity in order to increase the income of the farmers and promote food security in the country. In recognition of this potential, the Government committed itself to scale up investments so as to improve on its performance. For example, in 2001/2, the budget allocation as percentage of the total budget was 5.1 percent, 4.0 percent in $2005 / 6,4.3$ percent in $2007 / 8,5.0$ percent in 2010/11, 4.5 percent in 2011/12, and 3.7 percent in 2013/14 (Background to the budget

*Corresponding author: Tamson Nuwagaba K, Department of Business and Development Studies, Bishop Stuart University, Uganda, Tel: +256 485433468 E-mail: nawtamson@gmail.com

Received June 05, 2018; Accepted October 29, 2018; Published November 05 2018

Citation: Nuwagaba KT, Banugire RF, Milton RN (2018) Assessing the Impact of NAADS Programme on Agricultural Economic Performance in Mbarara District. Bus Eco J 9: 375. doi: 10.4172/2151-6219.1000375

Copyright: (C) 2018 Nuwagaba KT, et al. This is an open-access article distributed under the terms of the Creative Commons Attribution License, which permits unrestricted use, distribution, and reproduction in any medium, provided the original author and source are credited. 
2013/14). Despite the budget share that the government allocated to the agricultural sector, agriculture continues to face a number of challenges with a declining agricultural production and productivity thus increasing food insecurity and poverty levels among farmers in Uganda. The contribution of agriculture as per percent total GDP by $1995 / 6$ was 23.7 percent, $1998 / 9$ was 23.1 percent, 42 percent in 2001/2, 32 percent in 2005, 21 percent in 2007, 22.9 percent in 2011 and Gross Domestic Product (GDP) at current market prices stagnant at about 22 percent in 2013/14(UBOS). This fluctuation led to the formation of Plan for Modernization of Agriculture (PMA) to overcome the challenges that affected the agricultural production and productivity in the country in 2001.

The Plan for Modernization of Agriculture (PMA) was launched and implemented since 2001 with the vision of eradicating poverty through a profitable, competitive, sustainable and dynamic agricultural and agro-industrial sector and with the mission of transforming subsistence agriculture to commercial agriculture. It was based on the objectives of increase the income and quality of life of rural households, improve household food security through the market, generate gainful employment, and promote sustainable use and management of natural resources [1].

The PMA framework had seven priority pillars which include; research and technology development, national agricultural advisory services, agricultural education, improving access to rural finance, agro-processing and marketing, sustainable natural resource utilization and management and physical infrastructure improvement for making easy access of market for agricultural products. It involved all activities whether national, district, public sector, donor or NGO funded, which were under the seven pillars, and based on the principles:

- Reducing the rural poverty;

- Addressing the concern of limited government role to public goods, market failure, or regulatory functions;

- Emphasis on deepening decentralization;

- Empowerment of the poor and local communities;

- Integration of gender and other crosscutting issues within planning processes;

- Encouragement of private sector provision of goods and services; and

- Develop a multi-sectoral approach to agriculture [1,2].

NAADS was one of the seven pillars of PMA. It started in 2001 with the objectives of promoting food security, nutrition and household incomes through increased productivity (output per enterprise) and market-oriented farming.

The NAADS Phase I began in 2001 in 6 trial districts (Arua, Kabale, Kibaale, Mukono, Mbarara, Soroti and Tororo), working within 24 sub-counties and was later rolled out to all districts and ended in June 2009.

In implementation of NAADS phase 1 , a number of challenges were encountered which include; include late disbursement of funds to district and sub counties where activities were implemented, embezzlement of funds, government disruption of activities, over pricing and distribution of poor quality of the technology, inputs supplied to farmers; Poor public relations and communication at Local Government (LG) level in conveying the message on provision of support to the six model farmers per parish, and A flawed selection process for the six model farmers led to community perception that only the 'rich' or those in political leadership were benefitting from NAADS programme. These challenges obviously have implications for outcomes (output growth, revenues and commercialization of agriculture) [3].

This led to the implementation of NAADS programme Phase II July 2010 with an innovative public-private extension service delivery approach, with the goal of increasing market-oriented agricultural production by empowering farmers to demand and control agricultural advisory services. NAADS was also a key component of the government's plan to reduce poverty by 28 percent by 2014 . The agricultural sector's performance was not impressive which indicated the prevalence of food insecurity increased to 66 percent in that year (UNHS2005/06).

NAADS phase III of Agricultural Technology and Agribusiness Advisory Services (ATAAS) in 2011 with the overall goal of raising agricultural incomes by transforming subsistence farming to commercial agriculture, through enhancing agricultural production and productivity in a sustainable manner, supporting value addition, and improving access to and sustainability of markets [4-6]. It is implemented in all the 112 Districts, 1364 Sub counties and 7342 Parishes. ATAAS introduces new elements of agricultural research and agricultural advisory /extension systems aimed at improving efficiency and effectiveness of the systems as well as broadening the scope of NAADS as a programme intervention.

Due to the challenges of Inadequate numbers and technical capacity of service providers in local governments, the limiting nature of the MTEF ceilings and the inconsistent flow of funds which jeopardizes crop agriculture activities at the peak season, Lack of accountability, poor transparency and Corruption in procurement, especially at lower implementation levels, the need to embed the advisory services much better within the technology development system, rigid procurement processes which slow down programme implementation and contribute significantly to the reluctance of suppliers to engage with NAADS led to the phasing off of the NAADS programme from the village farmers to the army as the new taskforce(Military)to practice NAAD [7].

\section{Problem statement}

NAADS programme started in 2001 with the key objective of promoting food security and nutrition, and household incomes through increased productivity and market-oriented farming. In fulfilment of this objective, the programme was to use the village level approach for farmer mobilization. Farmers were given agricultural inputs ranging from but not limited to seeds for planting, pigs, hens, cows and goats in different areas in order to improve productivity as well as incomes of households.

However, various evaluations were done on its performance and yielded mixed results. For instance, the OPM, 2005 evaluation on NAADS phase I in western Uganda, indicated that the programme had a positive impact on agricultural productivity (output per enterprise). Benin et al. [8] evaluated NAADS phase II, found out a positive change in agricultural revenue, food security and nutrition of participants in NAADS programme in Uganda.

MAAIF [5] evaluated NAADS phase II, found a negative impact on agricultural productivity in terms of output in crop and livestock since the bulk of inputs were distributed to relatively better off farmers and the level of support was not aimed at achieving quantified levels of production thus weakening the NAADS programme to reduce 
food insecurity in its areas of implementation. MAAIF [6] added that the NAADS programme increased on food insecurity with reduction of households taking only one meal a day in part of Western region. However, it also indicated that the scope of programme coverage was still very limited both in number of farmers reached as well as the level of agricultural production among categories of farmers, and livestock numbers have increased across all types; cattle, sheep, goats, poultry and others supported by NAADS interventions. Allan [9] (2010) on assessment of NAADS programme on banana productivity in Bushenyi district, found out that NAADS program had a negative impact on output and average size of bananas grown in Bushenyi district. This is happening at a point when the sector has been implementing the NAADS programme for over 13 years. The paradox of this trend is that we are witnessing most dramatic shift in the transfer of wealth from the people engaged in agriculture, to those engaged in services and industry sectors. Therefore, it is difficult to draw a line between the findings of these researchers. It is from this background that the researcher assessed the economic performance of NAADS programme as well as capacity of institutions in the programme implementation in Mbarara district.

\section{Objective of the Study}

The purpose of the study was to assess the impact of NAADS programme on agricultural economic performance in Mbarara district [10]. Agricultural economic performance was evaluated in terms of; level of commercialisation, and household income in both goat rearing and piggery among farmers in Mbarara district. This study was to show whether NAADS programme improved on the level of household income and commercialisation among NAADS farmers to create a significant difference from Non-NAADS farmers as well as to point out the main factors that influenced its performance in Mbarara district.

\section{Area of the study}

This study was conducted in the 2 NAADS implementing Sub-Counties of Mbarara District that is, Mwiizi sub-county and Nyamitanga division in Mbarara Municipality. The study covered
Wards of Katete, Ruuti Nsiikye in Nyamitanga Division and Parishes of Rukarabo, Ryamiyonga, Kigaaga, Ngoma and Bushere in Mwiizi Sub-county. This is because Mbarara was among the first districts where NAADS programme was implemented up to 2014 when the programme was shifted to UPDF as a new taskforce in implementation [7].

NAADS programme involved farmer capacity building through education, group formation and management through imparting skills and information to the farmers, farm inputs, and advisory services, directly influence economic performance in terms of household income, productivity, and commercialization.

The concept framework also shows a number of moderating factors that could affect the economic performance of the programme though the programme is in place [11]. These factors include; quality and quantity of farmers inputs that were distributed to the farmers, expertise of implementers (service providers, and NAADS Coordinators at local levels), monitoring and supervision, distribution of inputs and service delivery (accessibility of farm inputs), farmer's attitude towards the programme. These factors could influence the process of implementation and the economic outcomes of the programme in Mbarara district. NAADS programme is a communitybased programme promoting community economic development (CED) hence the importance of participation of community members for better economic and social outcomes [12].

\section{Methodology}

The study used a quasi-experimental design with 2 groups (treatment and comparison group). The study looked at NAADS farmers (as an experiment) and Non-NAADS farmers (comparison) involved in similar enterprises (Goat rearing and Piggery). The study also used a Difference in Difference model involving two independent samples to shows the interaction variables between the 2 pulled means (NAADS (treatment) - Non-NAADS (control) to test that Figure 1 is statistically significant [13].

The Difference between means was used to determine if there was

1.6. A Conceptual framework of NAADS Programme.

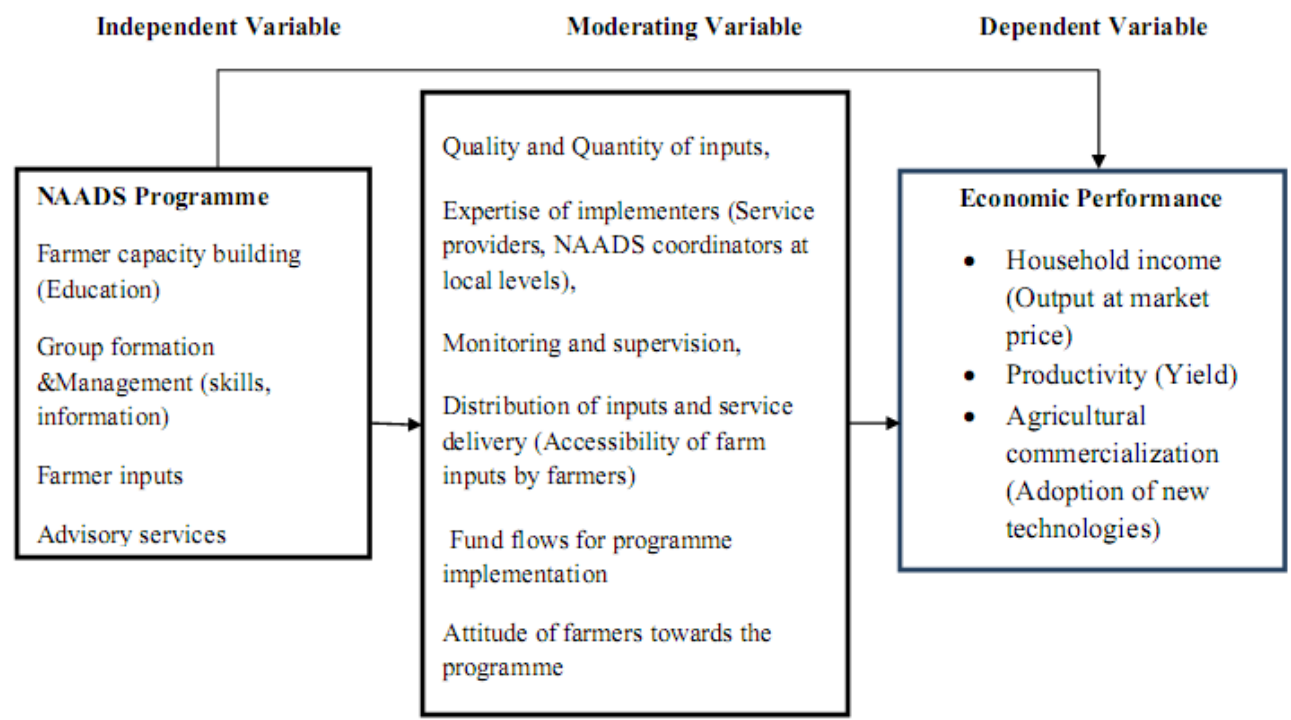

Figure 1: A conceptual framework of Economic performance of NAADS programme. It shows how NAADS programme package influenced the economic performance in terms of economic outcomes in agriculture sector. 
any significant difference between NAADS farmers and Non-NAADS farmers, and the variables (Commercialization, and Household income) in Mbarara district. This intended to show whether NAADS programme has contributed or not contributed to peasant agricultural commercialization, productivity and household income among the NAADS farmers in comparisons with Non-NAADS farmers in Mbarara district.

The study used a sample of 132 respondents for the NAADS and Non-NAADS farmers of both Goat rearing and Piggery and NAADS Coordinators that were involved in the programme from the district to Parish level in Mbarara district and were stratified and purposive sampled in Mwiizi sub-county and Nyamitanga division. These were distributed as 63 NAADS farmers of both enterprises (goat and pig rearing) and 6 NAADS Coordinators from two S/Counties as well as 63 Non-NAADS farmers from the same enterprises in both sub-counties. The study used both questionnaire survey and interview methods in collecting data from the field [14].

SPSS package was used to analyse the data. Independent Sample Test was used to obtain $\mathrm{p}$-value and $\mathrm{t}$-value. Descriptive statistics (mean and standard deviation) were generated to present the data. The statistics values were obtained were to indicate whether there is that there is statistical significant difference between NAADS and NonNAADS farmers in both goat rearing and piggery in Mbarara district.

\section{Major Findings of the Study}

\section{Level of commercialization}

This was determined by level of adoption of agricultural technologies by assessing the number of NAADS farmers through transferred the knowledge and skills learned from NAADS trainings on their own farms in form of recommended livestock and piggery management practices like modernized shelter for goats and pigs (modern houses for pigs and goats), improved breeds of goats and pigs and access to modern medicine for treatment among the NAADS farmers in Mbarara district.

Table 1, the mean differences (NAADS - Non-NAADS) in technology adoption show that there is no significant difference between NAADS and Non-NAADS farmers involved in goat rearing and piggery in Mbarara district. From the mean values between the two groups of NAADS and Non-NAADS in piggery and goat rearing are less than 3. This implies that NAADS programme did not contribute much on technology adoption through transferred the knowledge and skills learned from NAADS trainings like modernized shelter for goats and pigs (modern houses for pigs and goats), improved breeds of goats and pigs and access to modern medicine for treatment among NAADS farmers to create a significant difference from Non-NAADS farmers in technology adoption as one of its objectives [15]

The mean comparison in technology adoption between NAADS and Non-NAADS farmers under Levene's Test for equality of means is illustrated in the Table 2 .

Table 2 shows that the P-value is 0.168 in Sig. (2-tailed) column above 0.05 under equal variances not assumed in goat rearing, and in piggery P-value (Sig.0.120) above 0.05 under equal variance assumed [16-19]. These $\mathrm{p}$-values in the independent samples t-tests show that there is no statistical significant difference between the two groups (NAADS and Non-NAADS farmers) on commercialisation level. This implies that there is no sufficient evidence to conclude that NAADS programme intervention improved on the levels of agricultural commercialisation inform of agricultural technology adoptions through transferring knowledge and skills in goat rearing and piggery to make a difference between NAADS and Non-NAADS farmers in Mbarara district.

\section{Level of household income}

In the study, household income was measured by the quantity of the output (number of goat and pigs) in both goat rearing and piggery at the market price to determine the income $(\mathrm{Y})$ per annum of both NAADS and Non-NAADS farmers in Mbarara district.

The results from Table 3 the mean differences (NAADS - NonNAADS) in levels of income show that there is no significant difference between NAADS and Non-NAADS farmers involved in Goat rearing and piggery in Mbarara district. From the St. Deviation values between the two groups are less than 3 . This implies that NAADS programme did not contribute much in improving on household income as one of its objectives to make a difference between NAADS and Non-NAADS farmers in Mbarara district [20].

The mean comparisons in levels of income between NAADS and Non-NAADS farmers were also determined under Levene's Test for equality of means as shown in Table 4.

\begin{tabular}{|l|c|c|c|}
\hline Technology adoption & N & Mean & Std. Deviation \\
\hline Goat rearing(NAADS) & 38 & 1.5 & 0.50671 \\
\hline Goat rearing (NonNAADS) & 38 & 1.3421 & 0.48078 \\
\hline Piggery (NAADS) & 25 & 1.68 & 0.0822 \\
\hline Piggery (NonNAADS) & 25 & 1.44 & 0.4761 \\
\hline Source: Primary data. & & & 0.50662 \\
\hline
\end{tabular}

Table 1: Group statistics.

\begin{tabular}{|c|c|c|c|c|c|c|c|c|c|}
\hline \multirow{3}{*}{\multicolumn{2}{|c|}{$\begin{array}{l}\text { Level of commercialisation } \\
\text { Technology adoption } \\
\text { (NAADS\& Non-NAADS) }\end{array}$}} & \multicolumn{2}{|c|}{$\begin{array}{c}\text { Levene's Test for Equality of } \\
\text { Variances }\end{array}$} & \multicolumn{6}{|c|}{ t-test for Equality of Means } \\
\hline & & \multirow[t]{2}{*}{$f$} & \multirow[t]{2}{*}{ Sig. } & \multirow[t]{2}{*}{$\mathbf{t}$} & \multirow[t]{2}{*}{ df } & \multirow[t]{2}{*}{ Sig. (2-tailed) } & \multirow[t]{2}{*}{$\begin{array}{c}\text { Mean } \\
\text { Difference }\end{array}$} & \multicolumn{2}{|c|}{$\begin{array}{l}\text { 95\% Confidence Interval of the } \\
\text { Difference }\end{array}$} \\
\hline & & & & & & & & Lower & Upper \\
\hline \multirow[t]{2}{*}{ Goat rearing } & Equal variances assumed & 4.098 & 0.047 & 1.393 & 74 & 0.168 & 0.15789 & -0.06789 & 0.38367 \\
\hline & $\begin{array}{l}\text { Equal variances not } \\
\text { assumed }\end{array}$ & & & 1.393 & 73.797 & 0.168 & 0.15789 & -0.06789 & 0.38369 \\
\hline Piggery & Equal variances assumed & 2.508 & 0.12 & -1.726 & 48 & 0.091 & -24000 & -51957 & 0.03957 \\
\hline
\end{tabular}

Source: Primary data.

Table 2: Technology adoption by NAADS and NonNAADS farmers in Mbarara district, Independent samples test. 
Citation: Nuwagaba KT, Banugire RF, Milton RN (2018) Assessing the Impact of NAADS Programme on Agricultural Economic Performance in Mbarara District. Bus Eco J 9: 375. doi: 10.4172/2151-6219.1000375

Page 5 of 7

\begin{tabular}{|l|c|c|c|}
\hline Group Statistics & N & Mean & Std. Deviation \\
\hline Income & 38 & $4.45 E 5$ & $2.44 E 5$ \\
\hline Goat rearing(NAADS) & 38 & $2.81 E 5$ & $3.62 E 5$ \\
\hline Goat rearing(Non-NAADS) & 25 & $7.21 E 5$ & $6.24 E 5$ \\
\hline Piggery (NAADS) & 25 & $6.18 E 5$ & $5.67 E 5$ \\
\hline Piggery(Non-NAADS) & & & \\
\hline Source: Primary data. & & \\
\hline
\end{tabular}

Table 3: Level of income between NAADS and NonNAADS farmers in Mbarara district. (Million Shillings)

\begin{tabular}{|c|c|c|c|c|c|c|c|c|c|}
\hline \multicolumn{10}{|c|}{ Independent Samples Test } \\
\hline \multicolumn{2}{|c|}{$\begin{array}{l}\text { Level of income between NAADS and } \\
\text { Non-NAADA }\end{array}$} & \multicolumn{2}{|c|}{$\begin{array}{c}\text { Levene's Test for Equality of } \\
\text { Variances }\end{array}$} & \multicolumn{6}{|c|}{ t-test for Equality of Means } \\
\hline & & \multirow[t]{2}{*}{$\mathbf{F}$} & \multirow[t]{2}{*}{ Sig. } & \multirow[t]{2}{*}{$\mathbf{t}$} & \multirow[t]{2}{*}{ df } & \multirow[t]{2}{*}{$\begin{array}{c}\text { Sig. } \\
\text { (2-tailed) }\end{array}$} & \multirow[t]{2}{*}{$\begin{array}{c}\text { Mean } \\
\text { difference }\end{array}$} & \multicolumn{2}{|c|}{$\begin{array}{l}\text { 95\% Confidence Interval of the } \\
\text { Difference }\end{array}$} \\
\hline & & & & & & & & Lower & Upper \\
\hline \multirow[t]{2}{*}{ Goat rearing } & $\begin{array}{l}\text { Equal variances } \\
\text { assumed }\end{array}$ & 3.159 & 0.08 & 2.319 & 74 & 0.023 & $1.64 \mathrm{E}+05$ & 23139.9 & $3.05 E+05$ \\
\hline & $\begin{array}{l}\text { Equal variance not } \\
\text { assumed }\end{array}$ & & & 2.319 & 64.963 & 0.024 & $1.64 \mathrm{E}+05$ & 22813.11 & $3.06 \mathrm{E}+05$ \\
\hline Piggery & $\begin{array}{l}\text { Equal variances } \\
\text { assumed }\end{array}$ & 1.203 & 0.278 & 0.485 & 48 & 0.63 & $1.04 \mathrm{E}+05$ & $-3.26 E+05$ & $5.34 \mathrm{E}+05$ \\
\hline
\end{tabular}

Table 4: Level of the income between NAADS and Non-NAADS farmers in Mbarara district.

Factors that affected the economic performance

Expertise of implementers (Service providers, NAADS coordinators)

Monitoring and supervision

Distribution of inputs and service delivery

Funds flow to implement the NAADS programme

Attitude of farmers towards the programme

Quality and quantity of inputs distributed to farmers

Valid N (listwise)

Source: Primary data.

\begin{tabular}{|c|c|c|}
\hline $\mathbf{N}$ & Mean & Std. Deviation \\
\hline 63 & 2.1587 & 0.86521 \\
\hline 63 & 3 & 0.91581 \\
\hline 63 & 3.2381 & 0.99538 \\
\hline 63 & 3.0952 & 0.97904 \\
\hline 63 & 3.2381 & 0.99538 \\
\hline 63 & 3.254 & 0.99949 \\
\hline 63 & & \\
\hline
\end{tabular}

Table 5: Factors that influenced the economic performance of NAADS programme in Mbarara district

Table 4 shows that the p-value (sig.) for the Levene's test ( 0.08 and 0.278 ), are above 0.05 , assumed equal variances between two groups (NAADS and Non-NAADS) in both goat rearing and piggery. Sig (2-tailed) column shows that the p-value, it is 0.023 and 0.630 greater than 0.001 which is above cut-off point. Therefore, the results from $\mathrm{p}$-values in the independent samples t-tests show that there is no significant difference on levels of income between the two groups (NAADS and Non-NAADS farmers) involved in both goat rearing and piggery in Mbarara district [21]. This implies that there is no sufficient evidence to conclude that NAADS programme as an intervention in agriculture improved on the levels of household income of NAADS farmers to make a significant difference between NAADS and NonNAADS farmers in Mbarara district.

From Table 5 above, shows the mean and standard deviation values of the response from the data collected on the factors that affected the economic performance of NAADS programme in Mbarara district. Data was collected from NAADS farmers in both goat rearing and piggery in Mbarara district.

From the standard deviation and the mean values show that the main factors that greatly affected the economic performance of the programme include; monitoring and supervision, distribution of farm inputs and service delivery, fund flows to implement the NAADS programme, quality and quantity of inputs distributed to the farmers and the attitude of farmers towards the programme not the expertise of NAADS implementers especially NAADS coordinators at local levels and service providers to form groups, training among farmers, and education inform of capacity building greatly affected the economic performance of NAADS programme in Mbarara district [22].

Among the 6 respondents of key informants interviewed added that no enough funds to purchase more farm inputs for farmers and facilitate the service providers NAADS coordinators at local levels to carry out field tours in areas where the programme is implemented, no enough farm inputs to be distributed to the farmers, negative attitude towards government programmes like NAADS and corruption and embezzlement of funds at different levels of administration are the most important factors that affected the economic performance of NAADS programme in Mbarara district [23].

This indicates that monitoring and supervision, distribution of farm inputs, no enough funds, no enough farm inputs, attitude towards government programmes and corruption and embezzlement of funds are the most important factors that greatly affected the economic performance of NAADS programme in Mbarara district [24].

\section{Conclusion}

In conclusion therefore, basing on the results on the economic performance of NAADS Programme was not impressive. This shows that NAADS programme has not significantly promoted agricultural commercialization in terms of technology adoption among NAADS farmers, productivity and household income in Mbarara district. 
Basing on the findings, the level of monitoring and supervision, distribution of farm inputs and service delivery, no enough funds to facilitate the coordinators, and purchase inputs, no enough farm inputs, attitude of farmers towards government programmes and corruption and embezzlement of funds are the most important factors that greatly affected the economic performance of NAADS programme in Mbarara district.

\section{Recommendations}

Basing on the results on the performance of NAADS programme in Mbarara district, and the factors affecting the economic performance of NAADS programme, there is a need to pay attention to the above loopholes. The following are best practices for the improvement on the economic performance of NAADS programme in Mbarara district. These include;

The institution should increase the level of monitoring and supervision at different levels in the course of programme implementation, increasing in the accessibility of inputs and service delivery through farmers' groups' participation in decision-making. In terms funds for programme implementation, anti-corruption and embezzlement laws should be strengthened to eliminate private interests and promote transparency, accountability among the stakeholders in the implementation process for effective and sustainable use of resources allocated to the programme.

The NAADS programme need to be repackaged inform of enough facilitation, empowerment of the institutions like the local government, farmer groups and other civil society organisations(CSOs) and be given enough time to yield the results since the programme has been undergoing different changes in different phases before giving it enough time to produce the results. According to (MoFPED 2011), on the evaluation of this programme implementation showed that the institutional framework was inadequate for effective implementation of the programme. This was largely because of limited facilitation of staff, inadequate equipment as well as limited personnel. Both district and sub county NAADS coordinators noted the inadequate funding of programme operations. It is argued that institutions matter much in promoting economic growth and development of societies and communities' in which people live. Hoff. K and Stiglitz (2001, page 389 ) noted that development is no longer seen primarily a process of capital accumulation but rather as a process of organisational change.

The government should increase on the level of accessibility through fair distribution of farm inputs, constructing roads to connect rural areas where agriculture is done and marketing centers. This will increase the level of output of agricultural products as well as encouraging different programmes under the agricultural sector like NAADS programme thus increasing output, income and food security among rural people.

The government should reduce the negative attitudes of people towards the government programmes especially NAADS Programme. The research results indicated that under NAADS programme, there was uneven distribution of inputs (more inputs were distributed to better-off farmers) and no enough inputs since most of the farmers were registered and promised by the NAADS programme to be given goats and pigs and other inputs but up to now they are still waiting. Also, according to (MAAIF, 2011), indicated that the bulk of inputs were distributed to relatively better off farmers and the level of support was not aimed at achieving quantified levels of production. This weakened NAADS programme to reduce food insecurity if the quantities of the various foods to be produced were unknown. Therefore, the government should encourage positive attitude of people towards government programmes through sensitization of the rural farmers, even distribution of inputs, farmer's participation through strengthening farmer's group formation and increase farm inputs for farmers for accelerated progress in agriculture.

Pilot studies and consultations should be done in areas to help the stakeholders in identifying the appropriate inputs fit the farmers in those particular areas. Consultations will help increase the public participation thus inducing farmer's perceptions to change their societies and communities.

Rewarding the farmers with good performance/penalties to those with bad performance to motivate the farmers. This can increase competition among farmers to improve on the quantity and quality of the agricultural output in Mbarara district.

\section{Research Contribution}

The results from the field will help the policy makers to know the performance and implementation gaps in NAADS programme, the best practices for the success of any other agricultural policy in order to have the desired results. Therefore, the results in this study have identified the loop holes for the policy intervention. Findings are to help the new task force (Wealth Creation program) to show them strength and weaknesses existed in the previous implementation of NAADS programme in Mbarara district.

\section{Areas for Research}

Assessment of the capacity of the new taskforce for effectively implementing NAADS programme.

\section{References}

1. MFPED (2009) Budget Speech FY 2009/10/12.

2. Ministry of Agriculture, Animal Industry and Fisheries (MAAIF). Entebbe Uganda.

3. MoPED (2011) Financing the Food Security Budget in the National Agricultural Advisory Oriented Farmers. NAADS Secretariat, Kampala.

4. MAAIF (2011) Agriculture Sector Development Strategy and Investment Plan 2010/11-2014/15.

5. MAAIF (2011) Statistical Abstract, Entebbe, Uganda.

6. MAAIF (2011) NAADS Implementation Guidelines. Support to Food Security and Market.

7. The New vision 7th, July, (2014) NAADS programme banned

8. Benin S, Nkonya E, Okecho G, Pender J, Nahdy S, et al., (2011) Assessing the impact of the National Agricultural Advisory Services (NAADS) in the Uganda rural livelihoods. International Food Policy Research Institute (IFPRI).

9. Allan M (2010) Assessment of NAADS programme on banana productivity in Bushenyi district, Makerere University.

10. Bahiigwa G (2007) Understanding Prosperity for All in From Poverty to Prosperity, PMA Quarterly Bulletin.

11. Benin S, Thurlow J, Diao X, Kebba A, Ofwono N (2007) Agricultural Growth and Investment Options for Poverty Reduction in Uganda. International Food Policy Research Institute.

12. FAO (2007) Agricultural Investment and Productivity in Developing Countries, FAO

13. GoU (2006) National Agricultural Advisory Services (NAADS) Implementation Modalities. Ministry of Agriculture, Animal Industry and Fisheries (MAAIF) Entebbe, Uganda.

14. GoU (2007/2008) National Agricultural Advisory Services (NAADS) Quarter 
Citation: Nuwagaba KT, Banugire RF, Milton RN (2018) Assessing the Impact of NAADS Programme on Agricultural Economic Performance in Mbarara District. Bus Eco J 9: 375. doi: 10.4172/2151-6219.1000375

Progressive report. Ministry of Agriculture, Animal Industry and Fisheries (MAAIF) Entebbe, Uganda.

15. Griliches (2008) Measuring Agricultural Productivity Using the Average Productivity Index (API) by Lal Mervin Dharmasiri, Utrecht, University.

16. IFPRI (2007) Performance Evaluation of the National Agricultural Advisory Services (NAADS) in Uganda; Uganda.

17. MAAIF (2010) NAADS Implementation Guidelines.

18. Mashal, Ross (2006) Data collection methods and analysis. Oxford University Press.
19. New Vision (2007) The impact of NAADS programme on agricultural sector.

20. Office Prime Minister (2005) The assessment of performance NAADS programme in Western Uganda.

21. Dawning P (2007) Identifying a conceptual framework. Bournemouth University, Population and Housing Census.

22. Scanagri (2005) The impact of National Agricultural Advisory Service in Western Uganda.

23. The Republic of Uganda, National Agricultural Advisory Services (NAADS) New Implementation Guidelines (2008).

24. Uganda Bureau of Statistics (2002, 2005, 2008, 2011, 2012, 2013/14). 